University of Nebraska - Lincoln

DigitalCommons@University of Nebraska - Lincoln

\title{
Mathematics Deficiencies in Children with Very Low Birth Weight or Very Preterm Birth
}

\author{
H. Gerry Taylor \\ Case Western Reserve University, hgt2@case.edu \\ Kimberly A. Espy \\ University of Nebraska-Lincoln, kespy2@unl.edu \\ Peter J. Anderson \\ University of Melbourne, peterja@unimelb.edu.au
}

Follow this and additional works at: https://digitalcommons.unl.edu/dcnlfacpub

Part of the Neurosciences Commons

Taylor, H. Gerry; Espy, Kimberly A.; and Anderson, Peter J., "Mathematics Deficiencies in Children with Very Low Birth Weight or Very Preterm Birth" (2009). Developmental Cognitive Neuroscience Laboratory Faculty and Staff Publications. 42.

https://digitalcommons.unl.edu/dcnlfacpub/42

This Article is brought to you for free and open access by the Developmental Cognitive Neuroscience Laboratory at DigitalCommons@University of Nebraska - Lincoln. It has been accepted for inclusion in Developmental Cognitive Neuroscience Laboratory - Faculty and Staff Publications by an authorized administrator of DigitalCommons@University of Nebraska - Lincoln. 


\title{
Mathematics Deficiencies in Children with Very Low Birth Weight or Very Preterm Birth
}

\author{
H. Gerry Taylor, ${ }^{1}$ Kimberly Andrews Espy, ${ }^{2}$ and Peter J. Anderson ${ }^{3}$
}

\author{
${ }^{1}$ Department of Pediatrics, Case Western Reserve University, \\ Rainbow Babies and Children's Hospital, University Hospitals of Cleveland, \\ Cleveland, Ohio 44106-6038 \\ ${ }^{2}$ Office of Research and Department of Psychology, \\ University of Nebraska-Lincoln, Lincoln, Nebraska \\ ${ }^{3}$ Department of Psychology, The University of Melbourne, \\ Murdoch Children's Research Institute, Melbourne, Australia \\ Corresponding author - H. G. Taylor, email hgt2@case.edu
}

\begin{abstract}
Children with very low birth weight (VLBW, $<1500 \mathrm{~g}$ ) or very pre-term birth (VPTB, < 32 weeks gestational age or GA) have more mathematics disabilities or deficiencies (MD) and higher rates of mathematics learning disabilities (MLD) than normal birth weight term-born children (NBW, > $2500 \mathrm{~g}$ and $>36$ weeks GA). MD are found even in children without global disorders in cognition or neurosensory status and when IQ is controlled, and they are associated with other learning problems and weaknesses in perceptual motor abilities and executive function. Factors related to poorer mathematics outcomes include lower birth weight and GA, neonatal complications, and possible abnormalities in brain structure. While little is known about the nature of MD in these children, studies of MLD in other neurodevelopmental disorders and in children with learning disabilities provide useful models for further investigation. Further investigation of the neuropsychological and neuropathological correlates of distinct types of mathematics difficulties is also needed. Studies along these lines will yield information about the unique features of $\mathrm{MD}$ in children with VLBW/VPTB and about the nature and origins of poor mathematics achievement more generally.
\end{abstract}

Keywords: very low birth weight, mathematics learning disabilities, neuropsychological impairment

Advances in neonatal intensive care have resulted in increasing numbers of survivors with very low birth weight (VLBW, < $1500 \mathrm{~g}, 3 \mathrm{lbs} .5 \mathrm{oz}$.) or very preterm birth (VPTB, < 32 weeks gestational age, or GA) (Hintz et al., 2005). Although GA cut-offs provide a more meaningful basis for classifying the degree of prematurity, information on GA can be unreliable and birth weight markers are frequently used instead of GA to classify the degree of prematurity and fetal growth restriction. For this reason, children have been identified in the literature by either criterion and are referred to here as children with VLBW/VPTB. These children have high rates of neurological and other medical complications at birth and they are at risk for a variety of neurodevelopmental problems (Taylor, in press). Developmental consequences of VLBW/ VPTB range from cerebral palsy and mental retardation to more subtle deficits in cognitive abilities, academic achievement, and behavior in survivors without major handicapping conditions. Children born at more extreme degrees of VLBW/ VPTB, such as those with extremely low birth weight $(<1000$ g, 2 lbs. 3 oz.) or extremely preterm birth (GA $<28$ weeks) are at substantially higher risk for these disorders than are children with higher birth weight or GA.

Deficits in academic achievement occur in all basic skill areas (Klebanov et al., 1994; Saigal et al., 2000; Grunau et al., 2002; Anderson et al., 2003; Schneider et al., 2004; Feder et al., 2005; Litt et al., 2005; Taylor et al., 2000, 2006). These deficits are evident by school entry, persist throughout the school-age years, and are costly to treat (Chaikind and Corman, 1991; Saigal et al., 2000; Pharoah et al., 2003; Roth et al., 2004; Lefebvre et al., 2005). Many survivors have relatively selective impairments in academic skills, possibly related to specific neuropsychological weaknesses (Litt et al., 2005). Problems in mathematics are especially common but poorly understood.

In this article, we first review findings documenting the adverse effects of VLBW/VPTB on mathematics skills and summarize knowledge regarding factors related to these skills. Because the nature of mathematics difficulties in children with VLBW/VPTB has not been described in detail, we then consider studies of these problems in other populations, including children with other neurodevelopmental disorders and with developmental learning disabilities. These studies suggest ways to enhance knowledge of mathematics outcomes in children with VLBW/VPTB. In the final section we summarize methodological weaknesses of existing studies and promising directions for future research. Throughout the paper, the generic term mathematics disabilities (MD) refers to mathematics problems or deficiencies more broadly, while 
mathematics learning disabilities (MLD) refers to problems that are not accompanied by low global cognitive ability (e.g., as defined by IQs < 80-85) or neurosensory disorders, such as cerebral palsy, vision, or hearing impairments.

\section{Evidence for MD And MLD in Chil- dren with VLBW/VPTB}

Compared with groups of children with normal birth weight children born at term (NBW, $\geq 2500 \mathrm{~g}$ and 37 weeks GA), VLBW/VPTB cohorts consistently score at lower levels on tests of mathematics and receive lower teacher ratings of classroom performance in mathematics (Klebanov et al., 1994; Botting et al., 1998; Saigal et al., 2000; Taylor et al., 2002; Anderson et al., 2003; Hagen et al., 2006). The tests of mathematics skills administered in these studies have been limited to age standardized measures that assess accuracy in carrying out a range of arithmetic operations, most typically using either the Arithmetic subtest of the Wide Range Achievement Test (WRATR, WRAT3, WRAT4) or the Calculation and Applied Problems sub-tests of the Woodcock Johnson Tests of Achievement (original or revised versions). The Arithmetic and Calculation subtests measure written math skills (e.g., addition, subtraction, multiplication, division) and Applied Problems assesses arithmetic problem solving.

VLBW/VPTB samples score less well than NBW control groups on mathematics tests, even when excluding children with mental retardation or neurosensory disorders (i.e., cerebral palsy, vision, or hearing impairments) or when controlling for IQ (Klein et al., 1989; Klebanov et al., 1994; Botting et al., 1998; Saigal et al., 2000; Taylor et al., 2000; Taylor et al., 2002; Anderson et al., 2003). Results from several studies also indicate that children with VLBW/ VPTB have more pronounced impairments in mathematics than in reading (Klebanov et al., 1994; Breslau et al., 2001; Taylor et al., 2002; Anderson et al., 2003).

As further evidence for specific forms of MD, MLD are also more common in samples of children with VLBW/VPTB than in NBW groups. In the first phase of a longitudinal study conducted in Cleveland, Ohio, Taylor et al. (1995) examined rates of MLD and other forms of learning disabilities (LD) at mean age 7 years in a population cohort of children with $<750 \mathrm{~g}$ birth weight and matched groups of children with 750-1499 $\mathrm{g}$ birth weight and with NBW. Only children without neurosensory disorders and with standard scores of at least 80 on a measure of global cognitive ability were included. Subtests of the Woodcock Johnson Tests of Achievement-Revised were administered to assess mathematics (Calculation and Applied Problems), reading (Letter/ Word Identification), and spelling (Dictation). "Low achievement" LD was defined by standard scores $\leq 90$ on the achievement subtests, and "discrepancy-based" LD by scores below expectations (by at least 1.5 standard errors of the estimate) based on the child's global cognitive ability. Results revealed higher rates of low achievement LD in the $<750 \mathrm{~g}$ group compared with NBW controls on Calculation, Applied Problems, and Letter/Word Identification. The $<750 \mathrm{~g}$ group also had higher rates of discrepancy-based LD in Applied Problems. Differential rates of LD between the $<750 \mathrm{~g}$ and NBW groups were particularly large for the mathematics subtests, with rates of discrepancy-based LD in Applied Problems of about $60 \%$ in the $<750$ g group compared with 15\% in the NBW group. Rates of LD in the 750-1499 group fell between those in the other two groups but were not significantly higher than those for the children with NBW. Similar results were obtained in comparing the three groups followed in the Cleveland longitudinal study in rates of LD at mean age 11 years (Litt et al., 2005). The findings from the latter study also indicated a high degree of concordance of low achievement LD across the two assessments.

\section{$\bullet \bullet \bullet \bullet \bullet \bullet \bullet \bullet \bullet \bullet \bullet \bullet \bullet \bullet \bullet \bullet \bullet$ \\ VLBW/VPTB samples score less well than NBW control groups on math- ematics tests, even when excluding children with mental retardation or neu- rosensory disorders ... or when controlling for IQ.}

$\bullet \bullet \bullet \bullet \bullet \bullet \bullet \bullet \bullet \bullet \bullet \bullet \bullet \bullet \bullet \bullet$

In another study, Grunau et al. (2002) identified LD in mathematics, reading, and written output in a sample of children with $\leq 800 \mathrm{~g}$ birth weight and in
NBW controls. Only children with typical neurological development, with either a Wechsler Verbal or Performance IQ of at least 85, were included, and mathematics skills were assessed using the Arithmetic subtest of the WRATR. LD on this and other achievements tests were identified based on standard scores of less than 85 . The investigators found that $46 \%$ of the $\leq 800 \mathrm{~g}$ birth weight group had LD in Arithmetic compared with only $7 \%$ of the controls. The results of this study also documented a high rate of LD across multiple skill areas, with 10 of 22 children having LD in both Arithmetic and a reading measure. This rate of combined LD in mathematics and reading was similar to that observed in the study by Litt et al. (2005), where about half of the children with low achievement LD in mathematics also had low achievement LD in reading. Conversely, these data indicate that a sizable proportion of children with more extreme low birth weight have isolated MLD.

\section{Factors Related to MD}

\section{Degree of Low Birth Weight/GA}

The extent of MD varies along a continuum or "gradient" in proportion to the degree of VLBW/VPTB (Klebanov et al., 1994; Saigal et al., 2000; Taylor et al., 2000; Anderson et al., 2003; Schneider et al., 2004). Breslau et al. (2004) found a gradient effect on mathematics skills extending up to $2500 \mathrm{~g}$ birth weight. Specifically, MD in the low birth weight group relative to NBW controls were greater for children with VLBW but were also found in children with 2001$2500 \mathrm{~g}$ birth weight. A similar gradient is evident in studies of MLD. For example, Taylor et al. (1995) found that children with $<750 \mathrm{~g}$ birth weight had a higher rate of LD in Applied Problems than children with 750-1499 g birth weight; and Johnson and Breslau (2000) found that the rate of MLD among male children increased with lower birth weight throughout the $\leq 2500 \mathrm{~g}$ range.

\section{Medical and Brain Correlates}

Poorer mathematics skills at schoolage are related not only to the degree of VLBW/VPTB but also to neonatal complications and postnatal neurological abnormalities. In the Cleveland VLBW sample, scores on the Woodcock-Johnson Calculation and Applied Problems subtests at 7 years were independently associated with more neonatal compli- 
cations and lower birth weight (Taylor et al., 1998). Other studies indicate associations of poorer mathematics performance with more severe intraventricular hemorrhage, chronic lung disease (defined by placement on a ventilator for at least 36 weeks corrected age), treatment with postnatal steroids, necrotizing enterocolitis (infection and inflammation of the intestines), and longer neonatal hospitalization (Vohr et al., 2003; Sherlock et al., 2005; Taylor et al., 2006; Short et al., 2007).

Postnatal medical factors related to poorer educational outcomes include subnormal head circumference, vision problems, and abnormalities in brain structure. Peterson et al. (2006) observed that smaller head circumference at age 8 years was associated with lower scores on Calculation in children with VLBW from the Cleveland longitudinal study. These differences were found even when controlling for neurosensory abnormality, SES, sex, weight for GA, and neonatal medical complications. In examining outcomes of retinopathy of prematurity in a sample of children with 1250 birth weight, Msall et al. (2004) noted that poor visual acuity was associated with lower teacher ratings of mathematics. To our knowledge, only two studies have examined the postnatal neuropathological correlates of mathematics skills in children with VLBW/VPTB. Using magnetic resonance imaging (MRI), Isaacs et al. (2000) measured hippocampal volumes in a sample of adolescents with VLBW/VPTB accompanied by neonatal respiratory disease. Compared with agematched adolescents with normal birth histories, the VLBW/VPTB group had a selective impairment in mathematics computation that was accompanied by reduced bilateral hippocampal volumes. Group differences were not found in total intracranial volume, suggesting that structural alternations in the hippocampus may have contributed to the VLBW/ VPTB group's MLD. In a subsequent study, Isaacs et al. (2001) compared children from this same cohort whose scores in mathematics computation fell below expectation based on IQ with children from the cohort whose scores were consistent with IQ. MRI-based analysis revealed a reduction in brain volume in the group with MLD that was isolated to the left intraparietal lobe.

Based on evidence from functional MRI (fMRI), Dehaene et al. (2003) has postulated three brain regions that contribute uniquely to mathematics skills: an area of the intraparietal sulcus underlying quantity processing, a region in the left angular gyrus responsible for verbal processing of numbers, and a posterior superior parietal system related to spatial attention. Frontal brain regions are also selectively activated during mathematics tasks (Rickard et al., 2000). Patterns of activation that vary from those found in adults or children without VLBW/ VPTB would provide insights regarding compensatory brain organization. As illustrated by an fMRI study of children with phonological processing disorder (Noble et al., 2006), one possible outcome of such investigation is that children with activations in brain regions not typically engaged in mathematics tasks may have better mathematics skills than children with more typical, though perhaps diminished, activations. Several studies have observed atypical activations in response to cognitive tasks in survivors of VLBW/VPTB, supporting the possibility of compensatory mechanisms (e.g., Nosarti et al., 2006). To our knowledge, however, no studies of these children have examined activation patterns during mathematics tasks.

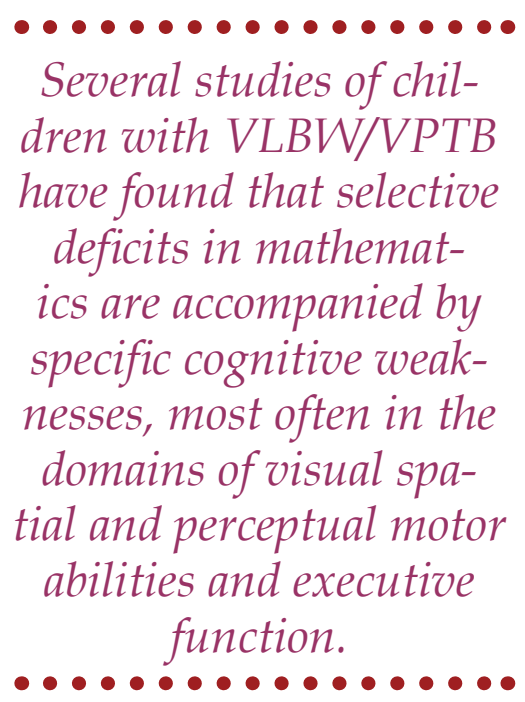

\section{Cognitive Correlates}

Several studies of children with VLBW/VPTB have found that selective deficits in mathematics are accompanied by specific cognitive weaknesses, most often in the domains of visual spatial and perceptual motor abilities and executive function. Rickards et al. (2001), for example, found deficits in mathematics but not in reading or spelling in comparing their VLBW cohort at age 14 years with a NBW group. The VLBW cohort also had impairments on tests of visual processing, visual memory, and visual perceptual organization, but not in most IQ subtests. In another VLBW sample, Klein et al. (1989) found only deficits in mathematics and perceptual motor skills when analysis was limited to children with normal IQ. Similarly, in comparing their $<750 \mathrm{~g}$ birth weight and NBW groups, Taylor et al. (2002) observed that only differences in mathematics and a perceptual planning factor composite remained when controlling for IQ.

Studies that have directly examined the cognitive correlates of mathematics skills in VLBW/VPTB samples reveal associations with both general ability as assessed by IQ and multiple specific neuropsychological skills. To illustrate, Taylor et al. (2006) found that measures of global mental processing, executive function, motor skills, and picture naming were related to Woodcock-Johnson Calculation at mean age 8 years in a cohort of children with $<1000 \mathrm{~g}$ birth weight. Assessment of a sample with $\leq 800 \mathrm{~g}$ birth weight by Grunau et al. (2002) revealed correlations of Arithmetic scores on the WRAT-R with Wechsler Verbal IQ and performance on a design copying test. In a further study of this cohort, weaknesses in Arithmetic were also associated with deficits in motor coordination (Holsti et al., 2002).

Other studies suggest that specific neuropsychological skills are related to mathematics achievement even after taking global cognitive ability into account. Taylor et al. (1998) showed that measures of attention administered to children in the Cleveland longitudinal study at 7 years were related to performance on Woodcock-Johnson Calculation and Applied Problems when controlling for IQ. Later follow-up of this sample at 11 years revealed that measures of perceptual planning and verbal working memory in the children with VLBW were each associated with mathematics performance independent of IQ (Litt et al., 2005). Findings from structural equation modeling of this data set by Taylor et al. (2002) suggest that the effects of VLBW on mathematics outcomes were mediated by some of these same measures, providing even stronger support for a neuropsychological basis of MD in this sample.

Results from several studies indicate that cognitive abilities in early childhood can forecast later MD. Sullivan and McGrath (2003) observed associations between motor performance at 4 
years and mathematics at 8 years in a sample comprised of children with $\leq 34$ weeks GA and healthy NBW controls. Botting et al. (1998) demonstrated a similar association between motor skills at age 6 years and performance on a written mathematics test at 12 years in children with VLBW and their classmate controls. In another longitudinal study, Schneider et al. (2004) found that a composite of mathematics reasoning, size estimation, and visualization given to a VLBW/ VPTB cohort and matched NBW controls was related to tests of IQ and letter, number, and phonological knowledge administered 2 years earlier. Finally, Breslau et al. (2001) found that mathematics skills as measured by the Woodcock-Johnson Psycho-Educational Battery-Revised at age 11 years in their sample of children with $\leq 2,500$ $\mathrm{g}$ birth weight and NBW controls was predicted by IQ, perceptual motor, and phonological processing tasks administered at age 6 years. IQ at age 6 years also predicted mathematics skills in this sample at 17 years (Breslau et al., 2004).

Sex and Age Differences in Mathematics Outcomes

Some studies of children with VLBW/VPTM suggest more MD and MLD in males than in females (O'Callaghan et al., 1996; Johnson and Breslau, 2000), though other investigations have not found sex differences in this population (e.g., Saigal et al., 2000; Taylor et al., 2000; Grunau et al., 2004). With respect to potential age differences in MD, impairments on tests of mathematics achievement in VLBW/ VPTB cohorts are evident from the early school-age years and persist into adolescence and young adulthood (Saigal et al., 1990; Taylor et al., 1995; Botting et al., 1998; Saigal et al., 2000; Rickards et al., 2001; Hack et al., 2002). To our knowledge, only two studies have examined changes in mathematics performance longitudinally in children with low birth weight. Saigal et al. (2000) observed a greater decline in standard scores on the Arithmetic subtest of the WRAT-R from ages 8 years to adolescence (1216 years) in a subsample of their cohort with $<750 \mathrm{~g}$ birth weight compared with full-term controls. They suggest that the decline may reflect increases with age in demands on conceptual skills and written computations. Breslau et al. (2004), however, found stable MD across age in following their sample of children with $2500 \mathrm{~g}$ birth from ages 11 to 17 years. The differences between these two stud-

ies may reflect the greater concentration of higher risk children in the cohort followed by Saigal et al. (2000). While few longitudinal studies have been conducted, evidence to date suggests that the presence of early MD is a marker of ongoing impairment and is unlikely to reflect developmental lag.

\section{Because testing has been restricted to compos- ite measures of compe- tencies, this research has not differentiated the ef- fects of VLBW/VPTB on different types of mathe- matics skills, such as the ability to retrieve math- ematics facts, carry out procedures for solving written or story prob- lems, apply mathemat- ics concepts, or engage in nonverbal or visual-spa- tial reasoning.}

$\bullet \bullet \bullet \bullet \bullet \bullet \bullet \bullet \bullet \bullet \bullet \bullet \bullet \bullet \bullet \bullet \bullet$

\section{Methodological Critique of the Exist- ing Literature on Mathematics Out- comes of VLBW/VPBT}

Studies of the effects of VLBW/ VPTB on mathematics have been subject to the same methodological limitations that have plagued research on other outcomes (Aylward, 2005). To begin with, the consequences of VLBW/ VPTB vary across eras and centers due to subtle differences in perinatal and neonatal management practices (PintoMartin et al., 2004; Vohr et al., 2004). For this reason, outcomes are expected to vary to some extent across sites and birth cohorts. Second, many past studies have failed to carefully match NBW comparison groups to VLBW/VPTB samples or to control for background factors, such as socioeconomic status, histories of educational interventions, genetic background and parenting characteristics, and prenatal drug and alcohol exposures, in analysis of group dif- ferences. A recent population study confirmed the importance of the home environment and early learning experiences as influences on subsequent mathematics achievement at 10 years (Melhuish et al., 2008). The consequences of VLBW/VPTB on mathematics skills may be best assessed in studies that take as many of these other factors into account as is feasible. Third, MD are typically described only for total VLBW/ VPTB samples, rather than in high-risk subgroups classified according to birth weight/GA, neonatal complications, or postnatal neurological status. Research on "person-level" effects, as opposed to the more traditional emphasis on "variable-level" effects, supports the viability of this subgrouping approach (Muthen and Muthen, 2000). Other limitations include the need to consider the effect of major handicapping conditions, such as generalized mental deficiency and neurosensory deficits in evaluating outcomes, and to document effects in terms of group differences in both mean performance and impairment rates.

Methodological weaknesses that are particularly limiting in understanding the effects of VLBW/VPTB include the failure of past studies to assess distinct types of MD, examine theory-based hypotheses regarding underlying neuropsychological competencies, and track developmental changes in mathematics skills. Because testing has been restricted to composite measures of competencies, this research has not differentiated the effects of VLBW/VPTB on different types of mathematics skills, such as the ability to retrieve mathematics facts, carry out procedures for solving written or story problems, apply mathematics concepts, or engage in nonverbal or visual-spatial reasoning. Past studies have also neglected to examine the nature of errors on mathematics tasks for clues as to the basis of incorrect answers to problems. A related problem is that, unlike the broader field of MLD research, research on MD in children with VLBW/VPTM has been largely atheoretical and in general has failed to explore associations of MD with distinct cognitive functions such as working memory, processing speed, mental flexibility, and attentional control. With respect to longitudinal follow-up, few studies have assessed mathematics skills in children with VLBW/ VPTB across age, and none to our knowledge has examined different types of mathematics skills or error types over time. 
Relevant Research on Other Neurodevelopmental Disorders and on Developmental MLD

Research on MLD in children with other neurodevelopmental conditions and on developmental MLD provides useful models for future studies of mathematics outcomes of VLBW/ VPTB. Specific problems in this area are characteristic of a number of neurodevelopmental disorders besides VLBW/ VPTB, including Turner syndrome, fragile $X$ syndrome, chromosome 22q11.2 deletion syndrome, hydrocephalus and spina bifida myelomeningocele (SBM), acute lymphocytic leukemia, and traumatic brain injury (Ayr et al., 2005; Barnes et al., 2007). Investigation of patterns of errors in arithmetic computation suggests distinct types of problems in some of these populations. Two studies found that children with hydrocephalus made more procedural errors on written problems (e.g., borrowing across multiple zeros), but not more errors in fact retrieval (e.g., 2 +7 ) or visually based errors (e.g., due to misalignment of rows or columns), than comparison groups without this condition (Barnes et al., 2002; Ayr et al. 2005). The children with hydrocephalus assessed by Barnes et al. (2002) also scored below typically developing controls on tests of geometry, division, mental computation, magnitude estimation, time and money concepts, and problem solving. In a study using similar methods, girls with Turner syndrome made more operation errors (e.g., subtracting instead of adding) and alignment errors (e.g., incorrect placement of decimal points) than girls with fragile $\mathrm{X}$ syndrome, whereas the groups did not differ in procedural errors (Mazzocco, 1998). Investigations of strategy use during mental computation and associations of written computation errors with neuropsychological skills provide further evidence for disorder-specific sources of MLD (Mazzocco, 1998, 2001; Ayr et al., 2005; Barnes et al., 2006). The unique correlates of different disorders may well reflect their distinct pathologies. A related observation from studies of children with developmental MLD is that specific types of MLD have distinct neuropsychological correlates (Geary, 1993; Mazzocco, 2001; Fuchs et al., 2005).

Another clue from studies of MLD in other populations is the importance of considering comorbid reading disabil-

ity. Barnes et al. (2006) observed more procedural errors in children with SBM who had MLD than in children with SBM without MLD regardless of reading status. However, only the subset with MLD plus reading disability made more errors in fact retrieval than typically developing children. The children with combined mathematics/reading disabilities, moreover, performed computations more slowly than children without reading disability. Studies of developmental MLD also show that the nature of mathematics problems varies in relation to presence or absence of comorbid reading disability. Children with isolated MLD have more circumscribed deficits in fact retrieval and progress more rapidly in mathematics than children with combined disabilities (Geary et al., 2000; Jordan et al., 2003). Postulated mechanisms for poor fact retrieval include deficient phonological representations, failure to inhibit memory for closely related facts, difficulties in manipulating nonverbal representations, and generally slow information processing (Jordan et al., 2003; Barnes et al., 2006). Landerl et al. (2004) identified a group of children with developmental MLD who did not have impairments in language or nonverbal abilities, suggesting cases of MLD with a relatively pure form of impaired numerosity processing.

\section{$\bullet \bullet \bullet \bullet \bullet \bullet \bullet \bullet \bullet \bullet \bullet \bullet \bullet \bullet \bullet \bullet$ \\ Research on MD in chil- dren with other neurode- velopmental conditions and on developmental MLD provides useful models for future studies of $M D$ in children with VLBW/ VPTB.}

Understanding of MD in children with VLBW/VPTB would be advanced by applying similar methodologies to this population. We know little about the nature of arithmetic error types in these children or about differences in mathematics skills in relation to accompanying reading disability. It is likewise unclear if children with deficits in arithmetic computations are prone to difficulties in magnitude estimation, ge- ometry, and money or time concepts, which would have important implications for survivors' long-term adaptive functioning. Although many children have isolated MLD, researchers have not characterized the nature and neuropsychological correlates of their difficulties in mathematics. Investigations of this sort would advance knowledge of the varieties of MD in children with VLBW/ VPTB and help identify characteristic impairments.

\section{Conclusions and Future Directions}

Advances in neonatal intensive care over the last several decades have resulted in survival of increasing numbers of children with wide-ranging developmental disabilities. The majority of these disabilities comprise relatively subtle learning and cognitive deficiencies in children without gross disturbances in mental ability or neurosensory function (Saigal and Rosenbaum, 2007). Academic deficits are most pronounced in the area of mathematics, though reading, spelling, and writing are also adversely affected in many children. Scores on mathematics tests are lower for VLBW/VPTB cohorts than for NBW controls even when children with major handicapping conditions are excluded from analysis or when IQ is controlled. VLBW/VPTB cohorts also have higher rates of MLD than NBW controls. These disabilities are frequently accompanied by LD in other domains, such as reading and written output (Grunau et al., 2002). However, MLD in children with VLBW/VPTB are more selective in nature than are reading and other speech and language-related disabilities (Samuelsson et al., 1999, 2000; Wolke et al., 2008).

That fact that MLD in children with VLBW/VPTB are correlated with deficits in perceptual motor skills and executive function independent of IQ provides further testimony to the selective nature of these problems (Litt et al., 2005). The combination of deficiencies in both mathematics and visual-perceptual skills, together with the high prevalence of abnormalities in white matter (Edgin et al., 2008), raises the possibility that MLD in these children are similar to the nonverbal LD described by Rourke (1993). However, injury to other brain structures, such as the hippocampus and parietal gray matter (Isaacs et al., 2000, 2001) may also contribute to 
MLD. Furthermore, potential implications for mathematics skills of insults to fronto-striatal and parietal-occipital pathways and the cerebellum are as yet unexplored (Allin et al., 2001; Jakobson et al., 2001; Woodward et al., 2006).

A better understanding of the MD and treatment needs of children with VLBW/VPTB can be promoted in several ways. First, more comprehensive assessments of mathematics skills are required to clarify the nature of their MD. Examples include measures of errors or fluency in fact retrieval and numerical operations, computational strategies, magnitude estimation, and comprehension of mathematics concepts (Mazzocco, 1998, 2003; Ayr et al., 2005; Gersten et al., 2005; Barnes et al., 2006). Such assessments may reveal subtle weaknesses that would otherwise go undetected and that may help to identify the unique features of MD in this population. Study of associations and dissociations between distinct varieties of MLD and disorders in reading or neuropsychological skills may also be useful in determining the types of problems to which children with VLBW/ VPTB are most vulnerable. The literature on MLD in this and other child populations suggests that multiple cognitive skills contribute to development of mathematics skills. A major goal of research involving children with VLBW/VPTB is to isolate the reasons for their MD. A plausible working hypothesis is that some of these deficiencies are due to global cognitive weaknesses affecting learning more generally, while other problems reflect insult to brain regions or circuits of particular relevance to mathematics.

Like other developmental outcomes of VLBW/VPTB, mathematics skills vary considerably within cohorts. This variability can be attributed to several factors. Biological risks for poorer mathematics outcomes are lower birth weight or GA, neonatal medical complications, and postnatal abnormalities in head circumference and brain structure. Other potential influences on these outcomes include prenatal exposures to drugs or alcohol, family and genetic background, past learning experiences, and behavioral dispositions and motivation. Contextual factors, such as the academic demands and the supports available to meet these demands, may be of additional importance is assessing mathematics performance at school. Consideration of these multiple risk and protective factors will clarify the effects of VLBW/VPTB and enhance prediction of individual outcomes.

In view of the fact that MD are more severe and selective in children with more extreme low birth weight or low GA, a sensible research strategy would be to focus on this segment of the VLBW/VPTB spectrum. It may also be useful to isolate high-risk subgroups with specific types of neonatal medical complications, such as chronic lung disease or neonatal brain insults. More information on residual neuropathology present at the time of follow-up from MRI would also illuminate the neural mechanisms contributing to mathematics difficulties, as would fMRI studies of brain activations during mathematics tasks.

Another important research direction is the study of early markers of mathematics difficulties in children with VLBW/VPTB and of the longer-term effects on academic progress and adult functioning. MD in school-age children are associated with weaknesses in global cognitive ability, perceptual motor skills, and academic readiness prior to or shortly after school entry (Breslau et al., 2001; Hansen et al., 2002; Sullivan and McGrath, 2003; Schneider et al., 2004). However, we know little about associations of neuropsychological impairments with early mathematics skills such as number concepts and counting. Longitudinal investigations have the potential to discover atypical trajectories of skill development and identify factors associated with these trajectories (Ansari and Karmiloff-Smith, 2002). Cross-age assessment of distinct types of mathematics skills and investigation of age differences in their cognitive correlates, as exemplified in a study by Ayr et al. (2005), would also provide information on developmental changes in the nature of mathematics difficulties in this population. We do not know if MD in some areas, such as mathematics reasoning, emerge with age as distinct disabilities or represent the cumulative effects of poorly developed basic skills in domains such as fact retrieval, math procedures, or mental representations of number. Evidence for increasing deficits across age in perceptual motor skills and executive function in children with $<750 \mathrm{~g}$ birth weight (Taylor et al., 2004) suggests that this subset of survivors may be especially prone to increasing difficulties in higher-level mathe- matics skills, but this possibility has not been tested.

Given the frequency of math problems in children with VLBW/ VPTB, interventions will be required to improve these outcomes. Methods that would have special relevance for children with VLBW/VPTB would be those that take into account their weaknesses in executive function, memory, and nonverbal abilities as well as their relative strengths in language (Litt et al., 2005; Taylor, in press). Approaches similar to those used in previous studies of children with developmental MLD would be appropriate given the needs of these children for structure and explicit strategy training, extended practice, and help in applying skills across multiple settings and problem types (Barnes, 2008). Because outcomes of VLBW/ VPTB are variable and needs may change with advancing age, flexibility will be required in accommodating to individual learning characteristics.

A related research direction is to explore reasons why many children with more extreme degrees of VLBW/ VPTB function well academically despite high-risk birth (Anderson et al., 2003). Acquisition of mathematics skills in these children may reflect relatively less severe neonatal brain insult but may also be related to greater brain plasticity or effective academic instruction. If so, study of these "success stories" may suggest ways to optimize the development of mathematics skills.

Research directed toward improved understanding of the nature and origins of MD in VLBW/VPTB samples will have several benefits. Practical benefits include information on the types and cognitive underpinnings of MD, so that these deficits can be more accurately identified and instructional interventions targeted to core areas of impairment. Knowing the types of MD to which children with VLBW/VPTB are most vulnerable will also help in designing interventions that may be broadly applicable to this population. Scientific benefits include the opportunity to examine specific neuropsychological and neural correlates of MD. Children with VLBW/VPTB are not only at high risk for selective deficits in mathematics but also have specific forms of neuropsychological impairment and neuropathology. Localized brain insults are in the very regions hypothesized to be most critical to math- 
ematics skills. Study of these children thus affords a unique opportunity to investigate cognitive and neural factors underlying specific forms of MD. Additional scientific advantages include opportunities to examine the influence of comorbid reading disabilities on mathematics achievement and to explore the possibility that some children may have deficits in numeracy skills that can not fully explained in terms of domain-general neuropsychological impairments.

\section{References}

Allin M, Matsumoto H, Santhouse AM, et al. 2001. Cognitive and motor function and the size of the cerebellum in adolescents born very pre-term. Brain 124:60-66.

Anderson P, Doyle LW, Victorian Infant Collaborative Study Group. 2003. Neurobehavioral outcomes of schoolage children born extremely low birth weight or very preterm in the 1990s. JAMA 289:3264-3272.

Ansari D, Karmiloff-Smith A. 2002. Atypical trajectories of number development: a neuroconstructivist perspective. Trends Cogn Sci 6:511-516.

Aylward GP. 2005. Neurodevelopmental outcomes of infants born prematurely. J Dev Behav Pediatr 26:427-440.

Ayr LK, Yeates KO, Enrile BG. 2005. Arithmetic skills and their cognitive correlates in children with acquired and congenital brain disorder. J Int Neuropsychol Soc 11:249-262.

Barnes MA, Fletcher JM, Ewing-Cobbs L. 2007. Mathematical disabilities in congenital and acquired neurodevelopmental disorders. In: Why Is Math So Hard for Some Children?: The Nature and Origins of Mathematical Learning Difficulties and Disabilities, Berch DB, Mazzocco MMM, editors. Baltimore: Paul H. Brooks. p 195-217.

Barnes MA, Fuchs LS. 2008. Learning disabilities. In: Developmental-behavioral pediatrics: evidence and practice, Wolraich ML, Drotar D, Dworkin PH, et al. editors. Philadelphia: Mosby. p 445-466.

Barnes MA, Pengelly S, Dennis M, et al. 2002. Mathematics skills in good readers with hydrocephalus. J Int Neuropsychol Soc 8:72-82.

Barnes MA, Wilkinson M, Khemani E, et al. 2006. Arithmetic processing in children with spina bifida: calculation accuracy, strategy use, and fact retrieval fluency. J Learn Dis 39:174-187.

Botting N, Powls A, Cooke RWI, et al. 1998. Cognitive and educational outcome of very-low-birthweight children in early adolescence. Dev Med Child Neurol 40:652-660.

Breslau N, Johnson EO, Lucia VC. 2001. Academic achievement of low birthweight children at age 11: the role of cognitive abilities at school entry. J Abnorm Child Psychol 29: 273-279.

Breslau N, Paneth NS, Lucia VC. 2004. The lingering academic deficits of low birth weight children. Pediatrics 114:1035-1040.

Chaikind S, Corman H. 1991. The impact of low birthweight on special education costs. Health Econ 10:292-311.

Dehaene S, Piazza M, Pinel P, et al. 2003. Three parietal circuits for number processing. Cogn Neuropsychol 20:487-506.

Edgin JO, Inder TE, Anderson PJ, et al. 2008. Executive functioning in preschool children born very preterm: relationship with early white matter pathology. J Int Neuropsychol Soc 14:90-101.

Feder KP, Majnemer A, Bourbonnais D, et al. 2005. Handwriting performance in preterm children compared with term peers at age 6 to 7 years. Dev Med Child Neurol 47:163-170.

Fuchs LS, Compton DL, Fuchs D, et al. 2005. The prevention, identification, and cognitive determinants of math difficulty. $J$ Educ Psychol 97:493-513.

Geary DC. 1993. Mathematics disabilities: cognitive, neuropsychological, and genetic components. Psychol Bull 114:345-362.

Geary DC, Hamson CO, Hoard MK. 2000. Numerical and arithmetrical cognition: a longitudinal study of process and concept deficits in children with learning disability. J Exp Child Psychol 77:236-263.

Gersten R, Jordan NC, Flojo JR. 2005. Early identification and interventions for students with mathematics difficulties. J Learn Disabil 38:293-304.

Grunau, RE, Whitfield MF, Davis C. 2002. Pattern of learning disabilities in children with extremely low birth weight and broadly average intelligence. Arch Pediatr Adolesc Med 156:615-620.

Grunau RE, Whitfield MF, Fay TB. 2004. Psychosocial and academic characteristics of extremely low birth weight $(800$ g) adolescents who are free of major impairment compared with term-born subjects. Pediatrics 114:e725-e732.

Hack M, Flannery DJ, Schluchter M, et al. 2002. Outcomes in young adulthood for very-low-birth-weight infants. $N$ Engl J Med 346: 149-157.

Hagen EW, Palta M, Albanese A, et al. 2006. School achievement in a regional cohort of children born very low birthweight. $J$ Dev Behav Pediatr 27:112-120.
Hansen BM, Dinesen J, Hoff B, et al. 2002. Intelligence in preterm children at four years of age as a predictor of school function: a longitudinal controlled study. Dev Med Child Neurol 44:517-521.

Hintz SR, Kendrick DE, Vohr BR, et al. 2005. Changes in neurodevelopmental outcomes at 18 and 22 months' corrected age among infants of less than 25 weeks' gestational age born in 19931999. Pediatrics 115:1645- 1651.

Holsti L, Grunau RVE, Whitfield MF. 2002. Developmental coordination disorder in extremely low birth weight children at nine years. J Dev Behav Pediatr 23:9-15.

Isaacs EB, Edmonds CJ, Lucas A, et al. 2001. Calculation difficulties in children of very low birthweight: a neural correlate. Brain 124: 1701-1707.

Isaacs EB, Lucas A, Chong WK, et al. 2000. Hippocampal volume and everyday memory in children of very low birth weight. Pediatr Res 47:713-720.

Jakobson LS, Frisk V, Knight RM, et al. 2001. The relationships between periventricular brain injury and deficits in visual processing among extremely-low-birthweight $(<1000 \mathrm{~g})$ children. J Pediatr Psychol 26: 503-512.

Johnson EO, Breslau N. 2000. Increased risk of learning disabilities in low birthweight boys at age 11 years. Biol Psychiatry 47:490- 500.

Jordan JC, Hanich LB, Kaplan D. 2003. A longitudinal study of mathematical competencies in children with specific mathematics difficulties versus children with comorbid mathematics and reading difficulties. Child Dev 74:834-850.

Klebanov PK, Brooks-Gunn J, McCormick, MC. 1994. School achievement and failure in very low birthweight children. $J$ Dev Behav Pediatr 15:248-256.

Klein N, Hack M, Breslau N. 1989. Children who were very low birth weight: development and academic achievement at nine years of age. J Dev Behav Pediatr 10:32-37.

Landerl K, Bevan A, Butterworth B. 2004. Developmental dyscalculia and basic numerical capacities: a study of 8-9year-old students. Cognition 93:99-125.

Lefebvre, F, Mazurier E, Tessier R. 2005. Cognitive and educational outcomes in early adulthood for infants weighing 1000 grams or less at birth. Acta Paediatr 94:733-740.

Litt J, Taylor HG, Klein N, et al. 2005. Learning disabilities in children with very low birth weight: prevalence, neuropsychological correlates, and educational interventions. J Learn Disabil 38:130-141. 
Mazzocco MMM. 1998. A process approach to describing mathematics difficulties in girls with Turner syndrome. Pediatrics 102:492- 496.

Mazzocco MMM. 2001. Math learning disability and math LD subtypes: evidence from studies of Turner syndrome, fragile $\mathrm{X}$ syndrome, and neurofibromatosis type 1. J Learn Disabil 34:520-533.

Mazzocco MMM. 2003. Complexities in identifying and defining mathematics learning disability in the primary school-age years. Ann Dyslexia 53:218-253.

Melhuish EC, Sylva K, Sammons P, et al. 2008. Preschool influences on mathematics achievement. Science 321:1161-1162.

Msall MD, Phelps DL, Hardy RJ, et al. 2004. Educational and social competencies at 8 years in children with threshold retinopathy of prematurity in the CRYOROP Multicenter Study. Pediatrics 113:790-799.

Muthen B, Muthen L. 2000. Integrating person-centered and variable-centered analyses: growth mixture modeling with latent trajectory classes. Alcohol Clin Exp Res 24:882-891.

Noble KG, Wolmetz ME, Ochs LG, et al. 2006. Brain-behavior relationships in reading acquisition are modulated by socioeconomic factors. Dev Sci 9:642-654.

Nosarti C, Rubia K, Smith AB, et al. 2006. Altered functional neuroanatomy of response inhibition in adolescent males who were born very preterm. Dev Med Child Neurol 48:265-271.

O'Callaghan MJ, Burns YR, Gray PH. 1996. School performance of ELBW children: a controlled study. Dev Med Child Neurol 38:917-926.

Peterson J, Taylor HG, Minich N, et al. 2006. Subnormal head circumference in very low birth weight children: neonatal correlates and school-age consequences. Early Hum Dev 82:325-334.

Pharoah POD, Stevenson CJ, West CR. 2003. General certificate of secondary education performance in very low birthweight infants. Arch Dis Child 88:295-298.

Pinto-Martin J, Whitaker A, Feldman J, et al. 2004. Special education services and school performance in a regional cohort of lowbirthweight infants at age nine. Paediatr Perinat Epidemiol 18:120-129.
Rickard TC, Romero SG, Basso G, et al. 2000. The calculating brain: an fMRI study. Neuropsychologia 38:325-335.

Rickards AL, Kelly EA, Doyle LW, et al. 2001. Cognition, academic progress, behavior and self-concept at 14 years of very low birth weight children. J Dev Behav Pediatr 22:11-18.

Rourke BP. 1993. Arithmetic disabilities, specific and otherwise: a neuropsychological perspective. J Learn Dis 26:214-226.

Roth J, Figlio DN, Chen Y, et al. 2004. Maternal and infant factors associated with excess kindergarten costs. Pediatrics 114:720-728.

Saigal S, Hoult LA, Streiner DL, et al. 2000. School difficulties at adolescence in a regional cohort of children who were extremely low birthweight. Pediatrics 105:325-331.

Saigal S, Rosenbaum P. 2007. What matters in the long term: reflections on the context of adult outcomes versus detailed measures in childhood. Semin Fetal Neonat Med 12: 415-422.

Saigal S, Szatmari $\mathrm{P}$, Rosenbaum $\mathrm{P}$, et al. 1990. Intellectual and functional status at school entry of children who weighed 1000 grams or less at birth: a regional perspective of births in the 1980s. J Pediatrics 116:409- 416.

Samuelsson S, Bylund B, Cervin T, et al. 1999. The prevalence of reading disabilities among very-low-birth-weight children at 9 years of age-Dyslexics or poor readers? Dyslexia 5:94-112.

Samuelsson S, Finnstrom O, Leijon I, et al. 2000. Phonological and surface profiles of reading difficulties among very low birth weight children: converging evidence for the developmental lag hypothesis. Sci Stud Reading 4:197-217.

Schneider W, Wolke D, Schlagmuller M, et al. 2004. Pathways to school achievement in very preterm and full term children. Eur J Psychol Edu 19:385-406.

Sherlock RL, Anderson PJ, Doyle LW, et al. 2005. Neurodevelopmental sequelae of intraventricular hemorrhange at 8 years of age in a regional cohort of ELBW/ very preterm infants. Early Hum Dev 81:909-916.

Sullivan MC, McGrath MM. 2003. Perinatal morbidity, mild motor delay, and later school outcomes. Dev Med Child Neurol 45:104-112.

Short EJ, Kirchner L, Asaad GR, et al. 2007. Developmental sequelae in preterm in- fants having a diagnosis of brochopulmonary dysplasia. Arch Pediatr Adolesc Med 161:1082- 1087.

Taylor, HG. Children with very low birth weight or very preterm birth. In: Pediatric Neuropsychology: Research, Theory, and Practice, Second Edition, Yeates KO, Ris MD, Taylor HG, et al. editors. New York: Guilford (in press).

Taylor HG, Burant C, Holding PA, et al. 2002. Sources of variability in sequelae of very low birth weight. Child Neuropsychol 8:164-178.

Taylor HG, Hack M, Klein N, et al. 1995. Achievement in children with birth weights less than 750 grams with normal cognitive abilities: evidence for specific learning disabilities. I Pediatr Psychol 20:703-719.

Taylor HG, Hack M, Klein N. 1998. Attention deficits in children with $<750$ gm birth weight. Child Neuropsychol 4:21-34.

Taylor HG, Klein N, Drotar D, et al. 2006. Consequences and risks for $<1000$ $\mathrm{g}$ birth weight for neuropsychological skills, achievement, and adaptive functioning. J Dev Behav Pediatr 27:459-469.

Taylor HG, Klein N, Minich N, et al. 2000. Middle school-age outcomes in children with very low birthweight. Child Dev 71:1495-1511.

Taylor HG, Klein N, Schatschneider C, et al. 1998. Predictors of early school age outcomes in very low birthweight children. J Dev Behav Pediatr 19:235-243.

Taylor HG, Minich, NM, Klein N, et al. 2004. Longitudinal outcomes of very low birth weight: neuropsychological findings. I Inter Neuropsychol Soc 10:149-163.

Vohr B, Allan WC, Westerveld M, et al. 2003. School-age outcomes of very low birth weight infants in the Indomethacin Intraventricular Hemorrhage Prevention Trial. Pediatrics 111:e340-e346.

Vohr BR, Wright LL, Dusick AM, et al. 2004. Center differences and outcomes of extremely low birth weight infants. Pediatrics 113:781-789.

Wolke D, Samara M, Bracewell M, et al. 2008. Specific language difficulties and school achievement in children born at 25 weeks of gestation or less. J Pediatr 152:256-262.

Woodward LJ, Anderson PJ, Austin NC, et al. 2006. Neonatal MRI to predict neurodevelopmental outcomes in preterm infants. N Engl J Med 355:685-694. 